\title{
MicroRNA 124
}

National Cancer Institute

\section{Source}

National Cancer Institute. MicroRNA 124. NCI Thesaurus. Code C106407.

A 20 ribonucleotide sequence that is a final product of the processing of either MIR124-1 pre-miRNA, MIR124-2 pre-miRNA or MIR124-3 pre-miRNA. This oligonucleotide may be involved in the negative regulation of gene expression. 